patients recorded suggest the need for prophylactic treatment. We feel that once haematological remission has been achieved in patients with lymphoid blast crisis they should receive prophylactic irradiation and intrathecal chemotherapy, as the chances of developing meningeal leukaemia are high.

We are grateful to Professor A V Hoffbrand for the TdT assays and to other members of our departments who have been concerned with these patients.

RKW is research fellow in clinical science of the National Health and Medical Research Council of Australia.

1 Janossy, G, et al, British fournal of Haematology, 1976, 34, 179.

3 Peterson, L C, Bloomfield, C D, and Brunning, R D, American fournal of Medicine, 1976, 60, 209.

4 Schwartz, J H, et al, American fournal of .Medicine, 1975, 59, 819.

5 Atkinson, K, et al, Cancer, 1975, 35, 529.

(Accepted 25 August 1977)

Imperial Cancer Research Fund, Department of Medical Oncology, St Bartholomew's Hospital, London EC1A 7BE

R K WOODRUFF, FRACP, senior registrar

J S MALPAS, DPHIL, FRCP, director and consultant physician

P F M WRIGLEY, PHD, MRCP, consultant physician

T A LISTER, MRCP, senior lecturer EC1A 7BE

A M PAXTON, MRCPATH, consultant haematologist

Membrane Immunology Unit, Imperial Cancer Research Fund, Lincoln's Inn Fields, London

G JANOSSY, MD, PHD, research scientist
2 Janossy, G, Roberts, M, and Greaves, M F, Lancet, 1976, 2, 1058.

Department of Haematology, St Bartholomew's Hospital, London
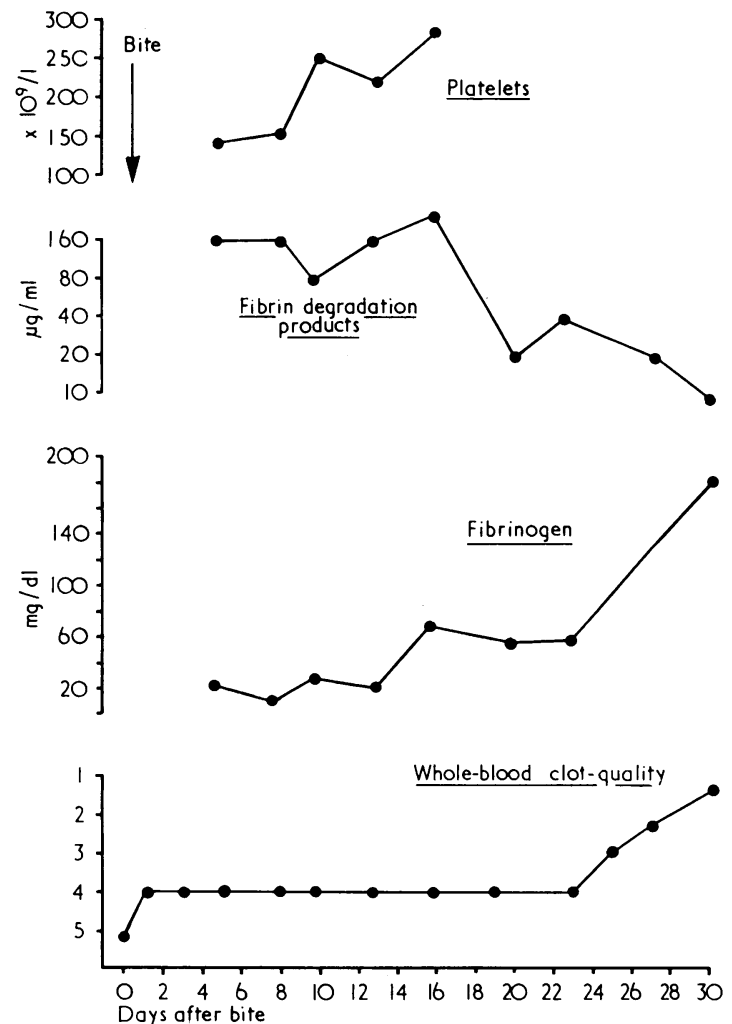

Duration of coagulation defect after the bite.

that time the results of serum urea and liver function tests (serum bilirubin, alkaline phosphatase, alanine aminotransferase) were normal.

\section{Prolonged defibrination syndrome after bite by the carpet viper Echis carinatus}

Snake bite is probably the most common cause of defibrination syndromes in the world. Although snake bite defibrination is remarkably benign in itself and not a primary cause of spontaneous bleeding, ${ }^{1}$ observing non-clotting blood is a vital bedside test that should alert doctors to the possibility of haemorrhage. The following case emphasises how important it is to monitor clot-quality in snake bite patients.

\section{Case report}

For venom research purposes I was "milking" Echis carinatus vipers on 25 February, 1975. The technique used is to grasp the viper's neck by forceps and then grasp the triangular head by a second forceps (the first forceps being released); the viper's neck is then held by the forefinger and thumb immediately behind the jaws-so close behind the jaws that this dangerously agile creature cannot turn its head and bite the milker. I had just released the second forceps but must have had my forefinger a trace too far back because I felt a painful prick at the top of my finger nail. The specimen was an adult $E$ carinatus, $48 \mathrm{~cm}$ long, from Northern Nigeria. I rapidly reapplied the head forceps, adjusted my grip, and completed milking the snake, which yielded venom weighing $18.5 \mathrm{mg}$ after freeze-drying.

Throbbing pain in the finger increased during the next hour and extended to the axilla. Swelling remained confined to the finger and had completely resolved without necrosis five days after the bite. Salivary spit was bloodstained five hours after the bite although hard coughing produced spit that was not bloodstained. On 26 February a discoid ecchymosis, $1 \mathrm{~cm}$ diameter, developed spontaneously over the right arm. No further haemorrhagic or other systemic signs were observed. Antivenom was not administered because poisoning, as judged by local effects, appeared mild and because I had previously had a severe antivenom reaction. ${ }^{2}$ I was surprised when a capillary clot-quality test four hours after the bite showed that my blood failed to clot, and even more surprised during the next four days that my blood continued to show a grade 4 "miniclot". ${ }^{1}$ From 2 March onwards my blood was therefore more extensively studied by methods previously outlined. ${ }^{3}$ The platelet count returned to normal 10 days after the bite, but it was 20 days later before clot-quality and concentrations of plasma fibrinogen and serum fibrin/fibrinogen degradation products returned to normal (see figure). At

\section{Comment}

So far as I am aware the longest duration of defibrination after snake bite previously recorded was 26 days after bites by the Malayan pit viper, Agkistrodon rhodostoma ${ }^{1}$; in such cases, local poisoning features, especially swelling, were pronounced. In my case local poisoning features were deceptively mild. In a study of $E$ carinatus bites in Nigeria, Warrell noted that local swelling could not be used as a clinical indicator of systemic poisoning; maximum natural duration of incoagulable blood observed was 10 days. ${ }^{4}$ What is the mechanism of this prolonged and sometimes recurrent defibrination? I assume there is a persisting depot of procoagulant toxin of which minute concentrations can cause total defibrination (experimentally, defibrination can last five to six days after subcutaneous injection of only $0.01 \mathrm{mg} E$ carinatus venom per $\mathrm{kg}$ in rats $^{5}$ ); and the toxin must be of relatively low antigenicity to man.

Since bites by $E$ carinatus are so common in many rural areas of Africa and Asia, there must be countless folk pursuing normal activities unaware they are "defibrinated." It is therefore fortunate that snake bite defibrination by itself is a relatively benign state. Defective clot-quality, however, may herald serious and possibly lethal haemorrhage-and haemorrhage that may be delayed until several days after the bite. ${ }^{4}$ Therefore, victims of snake bite (in the Western world if only for medicolegal reasons) should be competently observed until clot-quality remains consistently normal.

I thank Dr R D G Theakston for laboratory investigations and Mrs Heather Huxley for secretarial work.

1 Reid, H A, et al, Lancet, 1963, 1, 617 and 621.

2 Reid, H A, British Medical fournal, 1957, 2, 26

${ }^{3}$ Reid,. H A, and Sucharit, P, Lancet, 1972, 2, 1110.

4 Warrell, D A, et al, Quarterly fournal of Medicine, 1977, 46, 33

5 Kornalik, F, and Pudlak, P, Life Sciences, 1971, 10, 309.

(Accepted 29 fuly 1977)

Liverpool School of Tropical Medicine, Pembroke Place, Liverpool L3 5QA

H A REID, MD FRCP, senior lecturer 